\title{
SELF-REPORTED MUSCULOSKELETAL ACUTE AND OVERUSE INJURIES AMONG LATVIAN INFANTRY SOLDIERS
}

\author{
Darja Nesterovica \\ Riga Stradinš University, Military medicine research and study center, Latvia \\ Normunds Vaivads \\ National Armed forces, Joint Medical Service Headquarters, Latvia \\ Ainars Stepens \\ Riga Stradinš University, Military medicine research and study center, Latvia
}

\begin{abstract}
Musculoskeletal injury is the leading cause of disability among different military populations that results in socioeconomic burden and negatively affects military readiness. Study aim was to describe self-reported musculoskeletal injuries among Latvian infantry soldiers during one-year period. Survey-based cross-sectional study was carried out. Data was assessed using survey about injuries that occurred in one-year period during annual medical check-up. Musculoskeletal injuries were classified according to body regions as it is in Barell injury matrix and by injury type - acute or overuse. Study results showed in one-year injury incidence rate was 867.8 cases per 1000 person-years (95\% CI 824.8 - 913.0) with total 197 musculoskeletal injuries reported among active duty infantry soldiers. Typical acute injuries were superficial contusion injuries $(n=24)$, fractures $(n=21)$, joint dislocations $(n=21)$ and sprains $(n=29)$. Typical overuse diagnoses were lower back pain $(n=42)$, patellofemoral pain syndrome $(n=11)$, medial tibial stress syndrome $(n=9)$, plantar fasciitis $(n=8)$. Present study showed high incidence of overuse back injuries and overuse and acute lower leg injuries. Mostly of reported injuries could be classified as preventable and should be reduced through injury reduction programmes.
\end{abstract}

Keywords: Barell matrix, military personnel, musculoskeletal injuries, occupational health.

\section{Introduction}

Musculoskeletal injuries remain leading cause of disability among military population that results in socioeconomic burden and negatively affects military readiness among different countries. Half of all outpatient medical visits in U.S. appear to be due to injuries (Knapik et al., 2004). In the United Kingdom, musculoskeletal injuries are the primary cause of medical discharge among military population (UK Ministry of Defence, 2018).

Studies conducted in military injury epidemiology field usually are based on medical-record analysis; however, recent study showed high self-reported injury 
data accuracy when comparing with medical-record based data (Schuh-Renner et al., 2019).

Important aspect of injury prevention process is systematic injury surveillance, which monitors injury rates and trends (Jones et al., 2010; Schuh et al., 2017). For better understanding impact of injury reducing strategies, longterm monitoring of injury rates is recommended by Wardle \& Greeves (2017).

Latvian Land forces is the biggest branch of Latvian National Armed forces and infantry soldiers have consistently high physical demands. No epidemiologic data on musculoskeletal injuries among Latvian infantry soldiers have been published previously and first step for injury rates monitoring is survey usage for injury rate assessment. Therefore, purpose of this study is to describe self-reported musculoskeletal injuries among Latvian infantry soldiers during one-year period.

\section{Methods}

To assess self-reported musculoskeletal injury data we performed surveybased cross-sectional study. Latvian infantry soldiers were asked to fill in the survey about injuries that occurred in one-year period during annual medical check-up in State Military Medicine Centre. Participation was voluntary and written informed consent was retrieved after providing information on study purpose. Approvals for this research from Riga Stradinš university Ethics committee (Nr.40/26.10.2017) and Land forces of Latvia were admitted. Musculoskeletal injury was defined as an injury of any musculoskeletal system elements (bones, muscles, tendons etc.). Injuries were classified according to body regions as it is in Barrel injury matrix (Barell et al., 2002) and by injury type - acute or overuse. Barrel injury matrix is a basic tool for injury analysis; it displays twelve types of injury in columns and thirty six body regions in rows.

Musculoskeletal injuries due to blunt, crushing or penetrating trauma were classified as acute (Iannotti \& Parker, 2013). Injury caused by repetitive and/or forceful tasks as the result of repeated overstretching, overloading, deformation, compression, friction, or ischemia was classified as overuse injury (Kernan 2008; McCarty et al., 2017). For example, strains, sprains, ligament ruptures and fractures are acute injuries and overuse injuries are different tendinitis, bursitis etc. Stress fractures were included in overuse injury group due to micro-traumatic aetiology.

To describe injury incidence relative and absolute frequency distribution was used. Injury incidence calculated as number of injuries divided by the population at risk of an injury in a one-year period, results expressed as the number of injuries per 1000 person-years. For non-normally distributed data median values with standard deviation was reported. 
SOCIETY. INTEGRATION. EDUCATION

Proceedings of the International Scientific Conference. Volume VI, May $22^{\text {th }}-23^{\text {th }}, 2020.354-360$

\section{Results}

Totally 227 soldiers participated in survey, 94\% of survey participants were males at the mean age of $29.6 \pm 7.2$ years and with mean service time $7.1 \pm 6.4$ years. Participant characteristics are shown in Table1.

Table 1 The demographics of the subjects

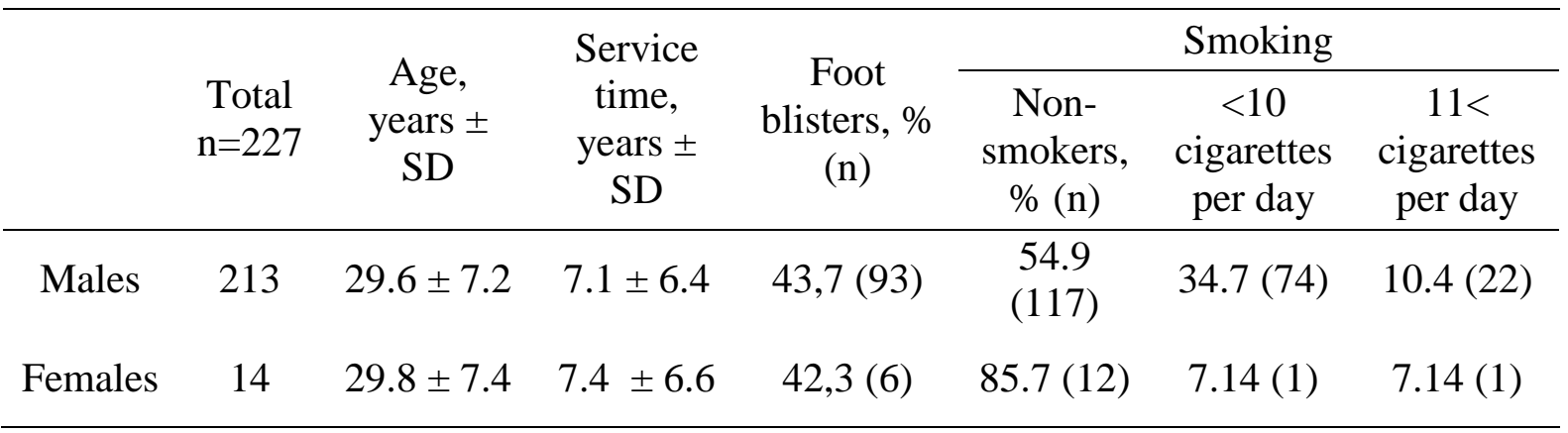

Overall, incidence rate reported 867.8 injuries per 1000 person-years (95\% CI 824.8 - 913.0) with total 197 musculoskeletal injuries reported in 2017 among active duty infantry soldiers. $45.6 \%$ of participants reported only one injury $(n=108), 26 \%$ reported two injuries $(n=59)$, and others reported three or more injuries $(\mathrm{n}=30)$.

Acute injury rate was 436.1 injuries per 1000 person-years (95\% CI 376.1 505.6); reported overuse injury rate was 431.7 injuries per 1000 person-years (95\% CI 371.8 - 501.2). Barrel injury matrix with listed acute and overuse injuries is in Table 2. Most common acute injury sites were lower leg and ankle, knee, wrist and shoulder.

Typical acute injuries were superficial contusion injuries $(n=24)$, fractures $(n=21)$, joint dislocations $(n=21)$ and sprains $(n=29)$. Acute injuries of abdomen and trunk, as well as any crush injuries, amputations or blood vessel injuries were not reported.

Overuse injuries were reported in $43 \%$ of cases ( $n=98)$. Most commonly injured locations due to overuse were lower back, knee, lower leg and foot. Typical overuse diagnoses were lower back pain $(n=42)$, patellofemoral pain syndrome $(n=11)$, medial tibial stress syndrome $(n=9)$, plantar fasciitis $(n=8)$. Metatarsal $(n=1)$ and fibular $(n=1)$ stress fractures were not common in this study. 
Table 2 Barrel injury matrix for acute and overuse injuries

\begin{tabular}{|c|c|c|c|c|c|c|c|c|c|c|}
\hline & & \multicolumn{7}{|c|}{ Acute injuries by type } & \multirow[b]{2}{*}{$\begin{array}{c}\text { Total } \\
\text { acute } \\
\text { injuries, } \\
n\end{array}$} & \multirow[b]{2}{*}{$\begin{array}{c}\text { Total } \\
\text { overuse } \\
\text { injuries, } \mathrm{n}\end{array}$} \\
\hline \multicolumn{2}{|c|}{$\begin{array}{l}\text { Body region of } \\
\text { injury }\end{array}$} & 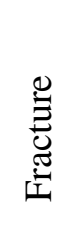 & 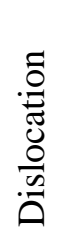 & 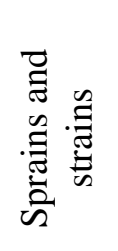 & $\begin{array}{l}\bar{\Xi} \\
\Xi \\
\vdots \\
\vdots \\
\bar{\Xi} \\
0\end{array}$ & 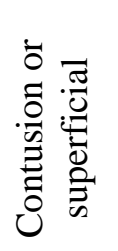 & 号 & $\sum_{z}^{\infty}$ & & \\
\hline \multirow{3}{*}{ 号 } & $\begin{array}{l}\text { Chest } \\
\text { (thorax) }\end{array}$ & 1 & - & - & - & - & - & - & 1 & 1 \\
\hline & $\begin{array}{c}\text { Pelvis } \\
\text { and } \\
\text { urogenital }\end{array}$ & - & - & - & - & 1 & - & - & 1 & - \\
\hline & $\begin{array}{c}\text { Back and } \\
\text { buttock }\end{array}$ & - & - & 1 & - & 2 & - & - & 3 & $42^{*}$ \\
\hline \multirow{8}{*}{ 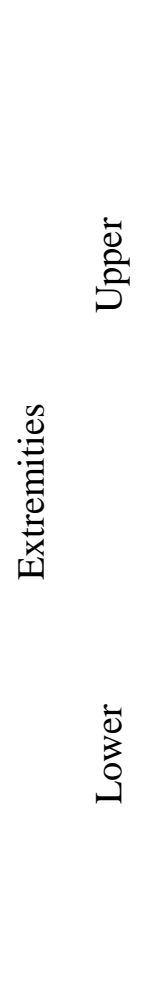 } & $\begin{array}{c}\text { Shoulder } \\
\text { and } \\
\text { upper } \\
\text { arm }\end{array}$ & 3 & 4 & 2 & - & 1 & - & - & 10 & 4 \\
\hline & $\begin{array}{l}\text { Forearm } \\
\text { and elbow }\end{array}$ & - & - & 2 & - & 4 & - & - & 6 & 6 \\
\hline & $\begin{array}{c}\text { Wrist, } \\
\text { hand, } \\
\text { and } \\
\text { fingers }\end{array}$ & 3 & 1 & 1 & 2 & 2 & 1 & - & 10 & 1 \\
\hline & Hip & - & - & - & - & 1 & - & - & 1 & - \\
\hline & $\begin{array}{l}\text { Upper leg } \\
\text { and thigh }\end{array}$ & - & - & 1 & - & 4 & - & 1 & 6 & - \\
\hline & Knee & - & 2 & 5 & - & 5 & - & - & 12 & 15 \\
\hline & $\begin{array}{l}\text { Lower } \\
\text { leg and } \\
\text { ankle }\end{array}$ & 11 & 14 & 16 & - & - & - & - & 41 & 17 \\
\hline & $\begin{array}{l}\text { Foot and } \\
\text { toes }\end{array}$ & 3 & - & 1 & - & 4 & - & - & 8 & 12 \\
\hline \multicolumn{2}{|c|}{ Total by injury type } & 21 & 21 & 29 & 2 & 24 & 1 & 1 & 99 & 98 \\
\hline
\end{tabular}

Note: *Injuries with incidence $\geq 10 \%$ are highlighted in bold

\section{Discussion}

Present study assessed self-reported musculoskeletal injury data among infantry soldiers. To authors' knowledge, this is the first descriptive study on epidemiology of injury data among Latvian infantry soldiers. Current research 
data provides information about most common acute and overuse injury types and locations based on survey data among infantry soldiers.

Acute and overuse injuries of lower extremity remain common among military populations, especially in infantry soldiers which is consistent with this study findings (Knapik et al., 2006). Most commonly lower back, knee, lower leg and foot were injured and these findings are similar to Abt et al. findings in US Army Operational Forces and Dijksma et al. recently reported injury locations in Netherlands Armed Forces (Abt et al., 2014; Dijksma et al., 2019). Orr et al. at self-reported injury study found bones and joints of lower extremity injuries as most commonly injured structure where most injuries occurred during marching (Orr et al., 2017). In this survey, few female soldiers participated and it reduces representativeness of injury rates found in this study. However, it has been reported that in military population females are have higher injury risks when comparing to males (MoD, 2018).

Acute musculoskeletal injuries, such as dislocations and sprains, according to Abt. et al. (2014), as well as overuse injuries identified in this study among infantry soldiers are classified as preventable in nature and prevention strategies should appear.

Observed overuse injury rate among all body regions at present study was 43\%, which is similar to 49\% reported by Lovalekar et al. in 2018 for U.S. Air Forces (Lovalekar et al., 2016).

Among all locations, lower extremity overuse has been reported with higher rates and it is similar to another study findings. For example, Ruscio et al. reported lower extremity overuse as the leading cause of limited duty in U.S. army (Ruscio et al., 2006).

Injury incidence rate calculation based on self-reported data is a strength and weakness at the same time. Smith et al. report, that approximately half of musculoskeletal injuries among infantry populations are not reported to medical personnel (Smith et al., 2016). However, self-reported injury data can also include injuries for which soldier did not seek any medical help or which were concealed from State Military Medicine centre doctors, so it helps to gain more comprehensive insight of injury prevalence.

Cross-sectional study design is a serious limitation in interpretation due to relatively small and heterogeneous study population, recall bias and honesty. Using surveys remain cost-effective method to gain data from large populations so in spite of study limitations, strength of this research is that it helps to gain insight to musculoskeletal acute and overuse injury sites. Recent study showed high self-reported injury data accuracy when comparing with medical-record based data, thereby additionally supporting survey data usage for injury assessment (Schuh-Renner et al., 2019). 


\section{Conclusions}

Overall self-reported injury incidence rate was 867.8 injuries per 1000 person-years. Present study showed high incidence of back and lower leg injuries. Reported injuries could be reduced through injury reduction programmes and in order to evaluate effectiveness of these programmes it is important to report injuries regularly and compare injury trends over time. Continuing injury monitoring allows implementing injury-oriented prevention strategy and assessing it effectiveness.

\section{Acknowledgement}

The author would like to thank soldiers who participated in the study and State Military Medicine Centre for the support.

\section{References}

Abt, J.P., Sell, T.C., Lovalekar, M.T., Keenan, K.A., Bozich, A.J., Morgan, J.S., Kane, S.F., Benson, P.J., \& Lephart, S.M. (2014). Injury Epidemiology of U.S. Army Special Operations Forces. Military Medicine, 179(10), 1106-1112. DOI: https://doi.org/10.7205/milmed-d-14-00078

Barell, V., Aharonson-Daniel, L., Fingerhut, L.A., Mackenzie, E.J., Ziv, A., Boyko, V., Abargel, A., Avitzour, M., \& Heruti, R. (2002). An introduction to the Barell body region by nature of injury diagnosis matrix. In Injury Prevention, 8(2), 91-96. DOI: https://doi.org/10.1136/ip.8.2.91

Dijksma, C.I., Bekkers, M., Spek, B., Lucas, C., \& Stuiver, M. (2019). Epidemiology and Financial Burden of Musculoskeletal Injuries as the Leading Health Problem in the Military. Military Medicine. DOI: https://doi.org/10.1093/milmed/usz328

Jones, B.H., Canham-Chervak, M., \& Sleet, D.A. (2010). An evidence-based public health approach to injury priorities and prevention: Recommendations for the U.S. Military. American Journal of Preventive Medicine, 38(1 SUPPL.). DOI: https://doi.org/10.1016/ j.amepre.2009.10.001

Knapik, J.J., Bullock, S.H., Canada, S., Toney, E., Wells, J.D., Hoedebecke, E., \& Jones, B.H. (2004). Influence of an injury reduction program on injury and fitness outcomes among soldiers. Injury Prevention, 10(1), 37-42. DOI: https://doi.org/10.1136/ip.2003.002808

Knapik, Joseph J., Darakjy, S., Hauret, K.G., Canada, S., Scott, S., Rieger, W., Marin, R., \& Jones, B.H. (2006). Increasing the Physical Fitness of Low-Fit Recruits before Basic Combat Training: An Evaluation of Fitness, Injuries, and Training Outcomes. Military Medicine, 171(1), 45-54. DOI: https://doi.org/10.7205/milmed.171.1.45

Lovalekar, M.T., Abt, J.P., Sell, T.C., Nagai, T., Keenan, K., Beals, K., Lephart, S.M., \& Wirt, M.D. (2016). Descriptive Epidemiology of Musculoskeletal Injuries in the Army 101st Airborne (Air Assault) Division. Military Medicine, 181(8), 900-906. DOI: https://doi.org/10.7205/milmed-d-15-00262

Neal, B.S., Griffiths, I.B., Dowling, G.J., Murley, G.S., Munteanu, S.E., Franettovich Smith, M.M., Collins, N.J., \& Barton, C.J. (2014). Foot posture as a risk factor for lower limb overuse injury: A systematic review and meta-analysis. Journal of Foot and Ankle 
Research, 7(1), 1-13. DOI: https://doi.org/10.1186/s13047-014-0055-4

Orr, R.M., Coyle, J., Johnston, V., \& Pope, R. (2017). Self-reported load carriage injuries of military soldiers. International Journal of Injury Control and Safety Promotion, 24(2), 189-197. DOI: https://doi.org/10.1080/17457300.2015.1132731

Ruscio, B., Smith, J., Amoroso, P., Anslinger, J., Bullock, S., Burnham, B., Campbell, J., Chervak, M., Garbow, K., \& Garver, R. (2006). DoD Military Injury Prevention Priorities Working Group: Leading Injuries, Causes and Mitigation Recommendations. DTIC Document, ADA458257, 88. DOI: http://www.dtic.mil/get-tr-doc/pdf?AD=ADA458257

Schuh-Renner, A., Canham-Chervak, M., Grier, T.L., \& Jones, B.H. (2019). Accuracy of selfreported injuries compared to medical record data. Musculoskeletal Science and Practice, 39, 39-44. DOI: https://doi.org/10.1016/j.msksp.2018.11.007

Schuh, A., Canham-Chervak, M., \& Jones, B.H. (2017). Statistical process control charts for monitoring military injuries. Injury Prevention, 23(6), 416-422. DOI: https://doi.org/10.1136/injuryprev-2016-042089

Smith, L., Westrick, R., Sauers, S., Cooper, A., Scofield, D., Claro, P., \& Warr, B. (2016). Underreporting of Musculoskeletal Injuries in the US Army: Findings From an Infantry Brigade Combat Team Survey Study. Sports Health, 8(6), 507-513. DOI: https://doi.org/10.1177/1941738116670873

Wardle, S.L., \& Greeves, J.P. (2017). A systematic review of the most effective injury prevention strategies for military personnel. Journal of Science and Medicine in Sport, 20, S3-S10. DOI: https://doi.org/10.1016/j.jsams.2017.09.014 